\title{
La Puerta de Noguera y la casa del presbítero Miguel López de Palma (Jaén)
}

\author{
Eloísa Ramírez de Juan*
}

\begin{abstract}
RESUMEN
A través del estudio de una casa descrita en el catastro del Marqués de la Ensenada se han conseguido nuevos datos sobre la Puerta de Noguera y de la Muralla adjunta.
\end{abstract}

PALABRAS CLAVE: Puerta, muralla medieval, urbanismo

La Puerta Noguera, de Noguera o de Las Nogueras, se situó al Sur de la ciudad. Sus restos marcan hoy el punto de separación entre las calles Alcantarilla y Manuel Jontoya (antes de La Noguera), en la confluencia con la calle Llana, hoy llamada de Francisco Coello, que desde este punto discurre en dirección Oeste, paralela al lienzo Sur de la muralla medieval de la ciudad y que articuló el ensanche renacentista del barrio de Santa María (Fig. I).

La Calle pertenecería a la parroquia o collación de San Ildefonso -como se sabe las collaciones no son espacios estancos con unos límites precisos (DÍEZ BEDMAR, 2002, RAMÍREZ DE JUAN, 200I) y una misma calle podría pertenecer a dos parroquias. (SALVATIERRA CUENCA, 1983) - una de las más pobladas o con mayor concentración de propiedades, según la infor-

\begin{abstract}
The study of a house described in the Catastro del Marqués de la Ensenada has provided new data concerning the Gate of Noguera and the adjacent maedieval wall.
\end{abstract}

KEY WORDS: Gate, mædieval wall, town planning

mación que aparece en el estudio que sobre Jaén en el siglo XVIII realizó el Deán Mazas en su Retrato al natural de la ciudad y término de Jaén, su estado antiguo y moderno (Ed. 1978).

No se conservan descripciones antiguas de la Puerta, pero podría tratarse de una gran construcción que abarcaría buena parte del ancho de la calle actual, y que tendría portillos peatonales a los costados, o quizá sólo uno al Oeste. Esto explicaría la importancia que la misma adquirió y que por ella pudieran transitar caballerías y comitivas como las de Enrique IV o el Condestable Iranzo, (CUEVAS MATA, DEL ARCO MOYA, Y DEL ARCO MOYA, 200I) etC. Semejantes a este modelo empiezan a hacerse algunas puertas, en otras ciudades, en la segunda mitad del siglo $X V$ y serán frecuentes en el XVI.

* Procedencia 
Esta hipótesis es la que puede deducirse de la descripción de los restos que hoy quedan (Lams. I a 4), que realizó M. López Pérez (1996):

Junto a la puerta Noguera existió un airoso "portillo" que facilitaba el tránsito peatonal. Un arquito de factura mudéjar, que perdida su primitiva función, en el siglo XVIII quedó encastrado entre los muros de la casa que el arquitecto Alonso de Lamas y Palma hizo a su sobrino el canónigo extravagante y maestro de ceremonias $D$. Miguel López de Palma.

En 1972 lo intentó reconstruir el arquitecto D. Luis Berges Roldán. Dicho elemento ha pasado por numerosos avatares en las últimas décadas (LÓPEZ PÉREZ, 1996).

\section{LA PUERTA Y LA MURALLA}

La función de esta puerta en relación con los accesos a la ciudad presenta cierta confusión. Para autores como J. Martínez de Mazas (1794) o P. Madoz (1845-50), se situaba en el lienzo de muralla principal de la ciudad, y a ellos les siguieron autores como J. Chamorro (1973). Consideraban que la muralla, tras pasar por detrás de la Catedral, bajaba hasta la Puerta Noguera, donde giraba y subía por la calle Abades hasta enlazar con la Torre del Alcotón, para dirigirse desde allí hacia el Oeste.

Posiblemente la primera que estudio en detalle este trazado fue $M^{a}$ S. Lázaro (1988), quien advirtió que dichos autores no habían tenido en cuenta que la construcción de la parte posterior de la Catedral implicó el derribo de la muralla, y que con toda probabilidad la Torre del Alcotón era la torre donde giraba la muraIla, por lo que la Puerta de Noguera había que relacionarla con los arrabales.

Para la autora mencionada, la Puerta de Noguera habría sido el acceso al Arrabal de Las Monjas, situado al Sur de la Catedral: “... debemos considerar como obra importante la adición a un nuevo tramo a la muralla en su vertiente sur aunque de exiguas dimensiones. Con él se unía el tramo existente entre las calles A. Noguera, Llana y Abades a la cerca, confluyendo en la Torre del Alcotón... Esta adición no tenía en su trazado ningún torreón y se abría a la Alcantarilla por medio de la puerta Noguera, de acceso recto y sin torres que la defendiesen."'(LÁZARO DAMAS, 1988:80).

Pero frente a esta posición otros autores consideraban que la Puerta daba en realidad acceso al arrabal de S. Ildefonso, ampliación de la ciudad realizada a finales de la época medieval. Así se deduce del croquis incluido en la $\mathrm{H}^{\mathrm{a}}$ de Jaén de 1982 (RODRIGUEZ MOLINA 1982:216), de los diversos intentos de reconstrucción del trazado de la muralla efectuados por V. Salvatierra a partir de 1993, y de las referencias contenidas en Díez Bedmar (2002) o Pérez Miñano (2004) entre otros, aunque ninguno argumenta de forma detenida su opción. En realidad, prácticamente ninguno de los dibujos publicados tiene en cuenta el Arrabal de Las Monjas, que dichos autores parecen considerar un recinto muy secundario, que ni siquiera dibujan, por lo que aparentemente dedujeron que la puerta Noguera, debía dar acceso al Arrabal de San Ildefonso. En cualquier caso de la confusión existente, dan idea las diferencias entre los distintos autores en relación a la ubicación de la puerta y a los elementos de la muralla anejos a la misma.

Recientemente V. Salvatierra (2004) en un nuevo análisis de conjunto, ha tratado de argumentar su posición. Dicho autor recuerda que durante el siglo XV la Puerta fue empleada frecuentemente para entrar y salir de la ciudad, y que como la propia $M^{a}$ Soledad Lázaro recoge, el Arrabal de las Monjas no tuvo comunicación directa con la ciudad hasta el año | 500, por lo que difícilmente la Puerta Noguera pudo ser el acceso a dicho Arrabal. Por el contrario, el de San Ildelfonso, sí se comunicaba desde el principio con la ciudad a través de la cercana Puerta de Sta. María, por lo que desde ella y a través de la de Noguera sí se salía de la ciudad. La muralla del Arrabal de Las Monjas, según este autor, partiría efectivamente de la Torre del Alcotón "con ligera dirección Sur, saldría por la calle Abades, donde existían restos de la misma y donde estaría el portillo de acceso al arrabal, cuya presencia ha quedado registrada en la calle 
del mismo nombre [Portillo]. Giraría luego hacia el Oeste, recorriendo la calle Llana, englobando parte de las calles paralelas a la de Abades (Julio Angel, etc.). La muralla llegaría a enlazar nuevamente con la principal en las inmediaciones de la Puerta de Granada, o en algún punto indeterminado de ese trazado". La Puerta Noguera se adosaría por el exterior al lienzo de muralla de la calle Abades y de ella partiría hacia el Este la muralla que rodearía el Arrabal de San Ildefonso (Fig. I).

Aunque el conjunto del problema parece estar ya resuelto, el análisis de la documentación relativa a la casa construida en el siglo $X V I I I$, que englobó gran parte de la puerta y los antecedentes de la misma, han proporcionado nuevos datos acerca de esta última, que creemos que contribuyen a aclarar algunos extremos.

En la actualidad estamos realizando un amplio estudio que pretende la reconstrucción del caserío urbano en el siglo XVIII, utilizando como fuente principal el Catastro del Marqués de la Ensenada, siendo el primer paso la creación de una completa Base de Datos sobre todas las propiedades citadas en el mismo. Hasta el momento he documentado más de 1500 casas ', según el Deán Mazas en Jaén existían unas 3500 .

En el curso de este trabajo localizamos la casa que fue derribada en los años setenta, a la que se refería M. López Pérez. De esta manera contamos con diversas fuentes acerca de la misma, entre ellas se encuentra una descripción muy completa y detallada lo que no es usual en dicho catastro, y diría que es excepcional contar además con la memoria y colaboración del arquitecto que trató de recuperar la Puerta Noguera 2 .

\section{LA CASA DE D. MIGUEL LÓPEZ DE PALMA}

La primera noticia documental sobre una casa junto a esta Puerta que aparece en los archivos consultados, es de 1521 y se refiere a su cesión a una viuda a la que se le encomienda la limpieza de la torre a cambio de habitar la casilla contigua, lo que suponía una costumbre de la época:

<Al margen: m(erce)d casa /puerta Inoguera> I este dya los dychos senor(e)s a suplicacyon de Mary Gu-ltyerez muger pobre le hyzyeron m(erce)d de la casylla de / junto a la puerta noguera para en q(ue) more por amor de dyos por qua(n)to la voluntad de la cibdad fuere I dexandola Ynygo de Cuellar q(ue) al presente mora en ella $/ 3$.

Durante la edad Moderna, los vecinos aprovechaban las murallas adosando viviendas a ellas, aunque estuviese prohibido, si bien los ayuntamientos autorizaban esta práctica a cambio de imponer censos (CORONAS, 1994) en este caso la casa del Presbítero López de Palma, tendría un censo perpetuo a favor de la ciudad de 30 reales.

No obstante, ignoramos si la casa de Mary Gutyerez se encontraba en el lado Oeste de la Puerta (área objeto de este estudio), o al lado Este. En cualquier caso, en el siglo XVIII, el maestro de albañilería y alcalde del Juzgado de alarifes de los edificios de la ciudad de Jaén, Alonso de Lamas y Palma ${ }^{4}$, construye por encargo de su sobrino el mencionado presbítero D. Miguel López de Palma la casa que figura en el Catastro del Marqués de la Ensenada, en declaración fechada concretamente el 23 de Febrero de 1752, que nos proporciona una descripción muy detallada de la distribución y

\footnotetext{
I A.H.P.J. Catastro Marqués de la Ensenada. Legajos 778I, 7782, 7784, 7785.

2 Quiero expresar mi agradecimiento por su generosa y desinteresada ayuda a D. Luis Berjes Roldán, arquitecto encargado de restaurar el Arco de la Puerta Noguera y los Baños Árabes de Jaén, entre otros edificios de interés cultural (Bic), como castillos, iglesias, conventos etc.

3 A.H.M.J. Actas capitulares, 28 de Agosto de 1521. Fol.317v. Documentación facilitada por D. Manuel Jódar Mena.

4 Alarife era el nombre dado a los maestros de obras y sobre todo a los albañiles.
} 
dimensiones, tanto del edificio como de cada una de las estancias, que ha posibilitado a $L$. Berges proporner la reconstrución que incluimos (Fgs. 2, 3 y 4):

Declaración de [Dn] (Don) Miguel Lopez de Palma $\left[\right.$ Presb $\left.{ }^{\circ}\right]$ (Presbitero) y $\left[\mathrm{M}^{\circ}\right]$ (Maestro) de [Zerems] (Ceremonias) / de la [St $\left.{ }^{a}\right]$ (Santa) [Ygla (Iglesia) de Jaen./ <Centrado: M> n 108 (Subrayado) Folio 379r. Posee el dicho una Casa en la Puerta Noguera, (la que havita) linda I por la parte de medio dia con el arco de la Puerta Noguera, i por la parte / del norte con casa que posee el Posito [desta] (de esta) Ciudad, por el poniente / con la Muralla; tiene la puerta al oriente por cima de dicho arco / un Çaguan de cinco varas de longitud, $i$ tres de latitud sobre el qual, I i un paso de la escalera tiene un despacho de cinco varas en quadro, I i sobre este una camara de cinco varas de latitud, i seis poco mas de / longitud vajo de la cual esta la escalera. = / una Cavalleriza de seis varas de longitud, i poco mas de tres de latitud, I sobre la cual ai una cozina, i el piso [desta] (de esta) es de la casa del posito. = / un patio con fuente de media cañon de Agua principal, i pozo, de / quatro varas de latitud, $i$ seis de longitud. $=$ vajo la escalera, i paso / de ella una vodega de cinco varas de longitud, $i$ tres de latitud. $=/$ una despensa vaxa quatro varas, $i\left[\mathrm{~m}^{a}\right]$ (media) en quadro, sobre esta / un quarto del mismo tamaño.= una antesala o corredor vajo de / seis varas de longitud, i tres, $i\left[\mathrm{~m}^{a}\right.$ ] de latitud, sobre la qual ai otra / del mismo tamaño, i sobre esta un frutero con su casquizami. Todo / del mismo tamaño.= una Sala vaja de Siete varas de longitud / i quatro de latitud, devajo una Cantina del mismo tamaño, sobre / dicha Sala ai otra del mismo tamaño, i sobre esta un granero, / i sobre este un terrado todo del mismo tamaño, un quartico encima / del arco de tres varas, $\mathrm{i}\left[\mathrm{m}^{a}\right]$ (media) de longitud, i dos de latitud dos huecos de la I muralla mui pequeños, i un corralillo de cinco [Vs.]
(Varas) de latitud, i tres de longitud. IPaga esta Casa de Censo perpetuo a la Ciudad. Todos los años. Treinta [rs.] / i otro Censo al [Sto.] (Santo) Christo del (Arquito) de S. Lorenzo de quarenta I y dos [RI] (Reales) i medio. Tiene esta figura su asiento <Margen derecho: croquis de la planta baja en la que figura la Sala vaja el, el Patio la Puerta, Cavallelriza, despensa y corredor> 1 Longitud de toda ella 19 [vr] (varas) / merece ganar 40 reales $/ 5$.

La declaración del Presbítero López de Palma nos dice que la casa tenía fuente y pozo, y aunque no aclara la procedencia del agua, podemos aventurar, por la zona de la ciudad en la que estaba situada, que sería del raudal de Santa María, uno de los que abastecían de agua a la ciudad (DíEZ BEDMAR, 1999). El edificio supone un claro ejemplo de encabalgamiento de habitaciones, ya que una de ellas pisaba sobre otra de la casa con la que lindaba, que era propiedad del Pósito de la ciudad. Con estas características existen varios casos en nuestra ciudad debido, entre otros motivos, a las acusadas pendientes de las calles ${ }^{6}$.

La casa no se conserva, pero la documentación consultada del XIX la situaba en el $n^{\circ}$ 10 de la calle Manuel Jontoya, denominada Arco de Noguera.

\section{CARACTERÍSTICAS CONSTRUCTIVAS DE LA CASA}

No hemos obtenido datos directos sobre los materiales utilizados para su construcción, ya que no era preceptivo realizar ningún tipo de intervención arqueológica en el momento del derribo de la casa, si bien sabemos por Madoz ( 1848) que se acostumbraba a construir con gruesas paredes de piedra o de buen tapial encajonadas en esquinas y pilares de piedra.

\footnotetext{
5 A.H.P.J. Castastro de Ensenada. Legajo 7781.

6 Hoy día existe una magnífica casa en el n 19 de la calle Llana, que pertenece a la familia del arquitecto, tristemente desaparecido, Manuel Millán López, que tiene una habitación sobre otra de la casa contigua. De esta vivienda encontré la primera nota registral de mediados del siglo XIX, pero por su estructura, distribución etc.., creo que podría fecharse en el siglo XVI.
} 
Los muros, por los restos encontrados de edificaciones de la misma época, podríamos asegurar que estaban formados por ripios, cal, arena, yeso y agua, junto con otros elementos procedentes de derribos, que posteriormente se cubrían con un revoco de cal.

Los forjados se realizaban con rollizos de troncos de pino, entrevedado con bovedilla de yeso. Sobre ello se colocaba ramaje de boj por ser un material imputrecible, al que se le añadía un relleno de tierra llamado alcatifa -terciopelo-, para amortiguar las pisadas (FATAS Y BORRÁS 1993), sobre este se vertía el mortero y se procedía a colocar la baldosa de barro cocido.

Las cubiertas solían ser inclinadas para facilitar la evacuación del agua de lluvia y en algunos caso de nieve; generalmente a dos aguas, aunque también las había a una sola vertiente o a cuatro cuando existía un patio central. El soporte, en caso de cubierta a dos aguas, consistía en una armadura de madera de forma triangular, formada por vigas - unidas entre sí por otras en sentido longitudinal, el nudillo- que apoyaban sobre la parte superior de los muros, bajo las cuales se situaban los terrados o cámaras. En el caso que nos ocupa existía un casquizami, creemos que puede ser una interpretación del término zaquizami ${ }^{7}$.

A finales del siglo XVIII, el Deán Martínez de Mazas ( I794) afirma que las casas eran regulares, con portal, con segunda puerta, patio claustrado, habitaciones en bajo para el verano, claustro alto con ventanas o balcones cristalados, y en alto estancias para el invierno, con cocinas en el mismo piso y una cámara con ventanas a la calle. Algunas de ellas tenían un tercer piso habitable. Tenían rejas a la calle y comenzaba a extenderse el uso de los balcones.
En la citada calle Llana, se conservan algunos edificios de esta época y, sin generalizar, ya que no todas las viviendas eran iguales, puesto que dependía del poder adquisivo y el estatus del propietario, podemos decir que tenían generalmente dos o tres plantas. La fachada se organizaba entorno a una puerta adintelada con jambas de sillería, balcones y ventanas. En los casos en que existía un tercer piso, que correspondería a las cámaras, observamos ventanas con arco de medio punto y de alguna de ellas, aún hoy pende una carrucha o polea para subir la carga, no olvidemos que Jaén fue una ciudad rodeada de huertos y una de las ocupaciones de sus ciudadanos era la agricultura.

\section{EL PROPIETARIO}

La casa pertenecía al presbítero y canónigo D. Miguel López de Palma, que vivió en Jaén a mediados del siglo XVIII. Era además, maestro de ceremonias extravagante. Con este término se hacía referencia a unos beneficiados que se diferenciaban de los canónigos normales en que no formaban parte del cabildo, como órgano de gobierno capaz de tomar decisiones (GARCÍA PARDO, 1998). Esta denominación aparece en documentos del siglo XVIII, concretamente en un pleito a cerca del hundimiento del camarín del Cristo del Perdón, también llamado del arquito de San Lorenzo, situado en el lienzo de muralla junto al portillo ${ }^{8}$.

\section{EL DERRIBO DE LA PUERTA}

En el siglo XIX era norma común derribar puertas de murallas y otros elementos de las ciudades que se encontraran en estado ruinoso ${ }^{9}$ o que entorpecieran la circulación de per-

\footnotetext{
7 Zaquizami. Del árabe "saaf sami”, desván, sobrado o último cuarto de la casa comunmente a teja vana. También techo sirio, nombre que se daba en Egipto al artesonado. (María Moliner 200 I).

8 A.C., A.H.D.J. Documentación facilitada por M.Amparo López Arandía.

9 Otro ejemplo de destrucción de puertas de ciudad lo encontramos en el caso del Arco de la Puerta de Granada. El 29 de Marzo de 1830 se inicia la agonía de este enclave de la muralla cuando el maestro de obras José Carrillo, declara el estado de ruina y aconseja su demolición, hasta que el 10 de abril de 1831 se consuma el derribo. A.H.M.J. Actas capitulartes. Localizado en Senda de los huertos n 7. "Papeles viejos". Jaén, 1985.
} 
sonas y cabalgaduras, y este era un punto neurálgico de la ciudad, un acceso para las caballerías que vendrían cargadas desde las numerosas huertas de los alrededores de la ciudad y la acentuada rasante de la calle sería un obstáculo añadido. Por ello el arquitecto provincial, José María Cuenca, tras una inspección realizada en virtud del Real Decreto de 14 de Marzo de 1860, denunció, en escrito de 5 de Marzo de 1867, que: "este Arco se viene abajo por estar ruinosas las dos casas paralelas que sirven de estribo al mismo, desplomadas y destrabadas..." y vuelve a recordar a la autoridad competente que disponga que los dueños de las casas citadas las apuntalen dentro del término de 3 días y presenten los planos de fachadas y alineamiento de calles al ayuntamiento, como previene el Excmo. Sr. Ministro de la Gobernación, lo que pone además en conocimiento del Gobernador cívico de la provincia ${ }^{10}$.

Años después, con fecha de 7 de Febrero de 1872, el arquitecto municipal Jorge P. (Porrua) Moreno emite un informe, para que se le haga llegar al entonces propietario de la casa D. Rafael Caro, a fin de que adopte las disposiciones que convengan para evitar el peligro que supone el Arco.

Reconocido el arco denominado de Noguera en virtud de la orden que V.I. se sirve darme con su muy antenta comunicación fecha de ayer tengo el honor de manifestarle; que atendida su estructura y diposición no de lugar a la duda que los cuarteos que se notan en su intrados en los estribos y en la fábrica sobre que se apoya son indicios evidentes de haber esperimentado notable alteración en su equilibrio y que por lo tanto debe considerarse como estado ruinoso y proximo a desplomarse con gran peligro para la circulación pública y no poco perjuicio de los predios limitrofes".
El 22 de Mayo de 1872, D. Ildefonso Gonzalez, como secretario interino del Ayuntamiento, certifica que a partir del dictamen que emitió la comisión de ornato se acordó que se destruyera el "Arco llamado de Noguera". Anexo I.

En relación a la citada demolición, ésta se llevó a cabo a pesar de la oposición del entonces propietario del inmueble adosado a la misma, D. Rafael Caro que interpuso, en 1872, un recurso de alzada contra el acuerdo del Ayuntamiento que autorizaba el derribo de dicha puerta ${ }^{12}$. El Alcalde Constitucional de Jaén, en respuesta a dicho recurso remite, con fecha 19 de Julio de 1872 el siguiente escrito:

"En contestación a la atenta comunicación de V. E. Fechada el 7 del corriente, debo manifestar que el Arco llamado de Noguera, en esta ciudad, subsiste en estado ruinoso, habiendo sido demolidas las habitaciones que sobre el mismo había. Respecto a las Ordenanzas municipales que se sirve pedirme adjunto tengo el honor de remitir a V.E. el Bando de Buen Gobierno, por el cual viene rigiéndose esta Municipalidad" 13 . (Legajo 2776/70. Archivo de la Diputación Provincial de Jaén).

Los motivos de tal derribo vendrían dados por ser una de las zonas más transitadas de la ciudad, un punto importante y de continuo movimiento, argumento recurrente que se utilizará posteriormente ya que es una práctica común de la época derruir estas edificaciones. El informe del Presidente de la Comisión de Ornato Jorge Porrúa Moreno, fechada el I de Mayo de 1872 está redactado en los siguientes términos: "en todas las poblaciones donde existan edificios de esta naturaleza se hacen por sus autoridades admninistrativas cuantos esfuerzos les son posibles para que desparezcan pues está prácticamente reconocido que no

\footnotetext{
10 A.H.M.J. Legajo 1684 (12),

I A.D.P.J. Legajo 2776/70.

12 A.D.P.J. Legajo 2776/70.

13 A.D.P.J. Legajo 2776/70.
} 
son convenientes para el ornato y salubridad pública, ni mucho menos para la seguridad y comodidad del transito". En este caso añade: "la manera como se ha empezado la reedificación de dicho arco la considero como insegura e indecorosa para una población que por su importancia actual y futura debe aspirar a mejorar su aspecto" y continúa diciendo dicho informe "en cuanto a la situación de este arco respecto a las calles que le están inmediatas, basta el sentido común para comprender que no puede ser pues forma una doble revuelta con todas las malas condiciones que se pueden imaginar y como es demasiado conocido de todos los habitantes de esta ciudad no he considerado necesario levantar el plano de ese sitio para poner de manifiesto este inconveniente para la viabilidad y seguridad pública". Se argumentaba además la "falta de espacio entre los estribos del arco, apenas suficiente para el paso de una caballería cargada y las rasantes pronunciadas de los dos tramos de calle que le están a uno y otro lado en el sentido del transito, que indudablemente es de lo más concurrido de la población por la importancia de los caminos que hay por ese lado". (Legajo, 2776/70. Archivo de la Diputación Provincial de Jaén).

También se alzaron voces privadas a favor del derribo, así lo confirma la instancia dirigida al Excmo. Ayuntamiento Constitucional de la ciudad por Da Agustina Coello, adjuntando el informe de la comisión de Ornato en la que se declaraba viuda y tutora de su hijo menor $D$. Vicente de Guardia, en la que exponía que la casa Calle Puerta Noguera $n^{\circ} 9$ propiedad de su hijo, fue reconocida por el maestro de obras D. Juan José Martos el cual certificó que la pared de la fachada donde estaba el arco llamado de Noguera, perteneciente a la casa $n^{\circ} 10$ cuyo propietario es D. Rafael Caro, "no se halla en condiciones de poder resistir la carga que naturalmente ha de sufrir al reconstruirse el indicado arco y oficinas que sobre esta y las paredes que les sustentan se han de elebar". Alegaba además que en caso de demoler las oficinas que existían sobre el mencionado arco por hallarse en estado ruinoso los golpes que se habían dado para su derribo y las perforaciones que se habían practicado en la casa $n^{\circ} 9$ para efectuar los apuntalamientos necesarios para con- solidar el arco, habían aumentado el mal estado de la mencionada pared de fachada, por lo que suplicaba se le retiraran los maderos utilizados para consolidar el arco mandados poner por el señor Caro. Este documento está fechado el 27 de Abril de 1872. (Legajo, 2776/70. Archivo de la Diputación Provincial de Jaén).

No era necesario un examen minucioso de la obra catalogada de "inconveniente, insegura y de desagradable aspecto" para que la comisión comprendiera la oportunidad de la medida tomada por la autoridad popular, pero no se limitó solamente a ese punto sino que consignó un dictamen completo en el que hacía alusión a los principios de higiene y salubridad pública, aparte de las consideraciones que hacían referencia al ornato y embellecimiento "de una población digna de avanzar aunque sea lentamente para conseguir una mejora aceptable".

El arquitecto municipal Jorge Porrua Moreno, después de haberla reconocido, había dictaminado que la construcción se encontraba en estado ruinoso, próxima a desplomarse y que suponía gran peligro para la circulación pública. Posteriormente procedió de nuevo a la inspección, vistos los documentos que acreditaban el estado ruinoso del citado sitio, constatando que la demolición se había verificado y eliminado el peligro de la vía pública.

\section{CONCLUSIÓN}

La casa, como ya hemos dicho, no se conserva, ya que en el siglo $X X$, en la década de los setenta, se demolió para ampliar la calzada como había sucedido cien años antes y con los mismos argumentos, el hecho de que fuera un estorbo para el tráfico de personas y vehícuIOS (CAZABÁN LAGUNA, 1930; ORTEGA Y SAGRISTA 1972; PARDO CRESPO, 1982; RAMÍREZ DE JUAN, 2004). Existe un torreón que pertenece a la casa $n^{\circ} 2$ de la calle Llana, que en la actualidad se encuentra habitada y en cuyos bajos desempeña su labor un barbero. Tenemos indicios de que puedan quedar más restos de él o de la muralla, además de los visibles hoy día, en algún inmueble, tras las sucesivas transformaciones sufridas por la manzana, algo por otro lado 
bastante frecuente, tal y como hemos ilustrado en párrafos anteriores. También se conserva la hornacina del Cristo del Arco de San Lorenzo.

Después del derribo de la casa, los intentos de recuperación de la puerta en los años setenta del siglo $X X$ han permitido obtener nuevos datos según los cuales la casa integraba en su estructura la mencionada Puerta y por el portillo tendría un acceso al corral ${ }^{14}$. Lindaba por el medio día con el arco de Puerta Noguera y por el poniente con la muralla. Tenía la puerta por encima del arco. La muralla de época Moderna bajaba por la calle Manuel Jontoya hasta la esquina con la calle Llana, donde se alzaba un torreón que estuvo adosado al arco de la puerta Noguera hasta los años setenta (BERGES ROLDÁN, 1996). El Torreón tenía tres plantas, en las dos primeras existían sendas habitaciones y en la tercera una azotea, y podría tener bodega ${ }^{15}$. La superficie en planta de la vivienda era de 152 varas castellanas, 19 de frente por 8 de fondo, que serían 126,820 $\mathrm{m}^{2}$.

La casa derribada integraría el portillo Oeste y los 2 torreones que lo flanqueaban uno de los cuales, el correspondiente a dicho lado parece que subsiste en la vivienda $n^{\circ} 2$ de la calle Llana. Si observamos los parcelarios, tanto el realizado por F. Revenga en 1945 (Fig. 5), como los de años posteriores (Fig. 6), podemos apreciar como se ha producido un alineamiento que conllevó la destrucción del torreón Este y su correspondiente arquito. Con estos datos podemos plantear que habría un lienzo de muralla junto la calle Manuel Jontoya, que subiría por la margen izquierda girando en algún punto para enlazar con la muralla medieval de la catedral donde existiría un portillo, extremo que podríamos confirmar cuando profundicemos en el estudio del resto de la manzana, ya que tenemos descripciones de otras viviendas que la componen.

A tenor de estos datos la Puerta podría consistir en una gran construcción que estaría formada de Oeste a Este por un pequeño portillo o paso del que se conserva el arranque, en la esquina de la calle Llana y Manuel Jontoya, un gran torreón y la puerta, esquema que se repetiría en el lado Este.

La Puerta de Noguera era unas de las más transitadas de la ciudad de Jaén durante Edad Moderna que daba acceso al arrabal de San Ildefonso y de ella arrancaba un lienzo de muralla que tendría una potencia de aproximadamente 1,20 m., que circundaría dicho arrabal. (Fot. I). No parece ser que la estructura de la que hablamos se limitara a un pequeño portillo, ya que éste solamente permitiría el paso de personas, y no de caballerías, carruajes o séquitos reales como los que describen las Crónicas del Condestable Iranzo (200I), por lo que tendría que haber una gran puerta que estaría situada en el lugar en el que hoy existe un ensanche utilizado como aparcamiento y no sabemos en que momento fue destruida.

Las distintas fuentes documentales han arrojado valiosa información, tanto para el estudio de la edilicia pública como de la privada, en este caso para el estudio de elementos vertebradores de la ciudad como pueden ser murallas, torres, puertas o portillos. También sobre la vivienda en general y los edificios singulares que pertenecieron a las élites; sobre la llamada arquitectura menor, las casas en las que vivían personas anónimas, que se dedicaban a todo tipo de actividades y que eran el motor de la ciudad. En resumen hemos encontrado documentación que nos puede ayudar a comprender como era la ciudad de Jaén en siglo XVIII.

\footnotetext{
14 Según comunicación verbal del arquitecto D. Luis Berges Roldán.

15 Datos aportados por el actual propietario.
} 


\section{ARCHIVOS CONSULTADOS}

A.H.P.J.: Archivo Histórico Provincial de Jaén.

A.H.D.J:: Archivo Histórico Diocesano de Jaén.

A.H.M.J.: Archivo Histórico Municipal de Jaén.

A.D.P.J:: Archivo de la Diputación Provincial de Jaén.

Biblioteca Municipal de Jaén: Hemeroteca

\section{BIBLIOGRAFÍA}

BERGES ROLDÁN, Luis: "Un tramo de la muralla sur de Jaén". Senda de los Huertos, núm. 7, págs. 55-57.

CAZABAN LAGUNA, Alfredo (1930): "Restos del otro Jaén. El torreón del Conde de Torralba", Don Lope de Sosa, pág. 210

CHAMORRO. J. (1973): "Las murallas de Jaén". Castillos de España, No 12, (segunda época), Madrid pp. 50-5I.

CORONAS TEJADA, Luis (1994). Jaén siglo XVII. Biografía de una ciudad en la decadencia de España. Jaén. pp. |4-|5.

DÍEZ BEDMAR, Ma. Consuelo (1999). El raudal de la Magdalena y el crecimiento urbano de Jaén, Jaén.

DÍEZ BEDMAR, M ${ }^{\mathrm{a}}$ Consuelo (2002). Urbanismo y sociedad de Jaén en época bajomedieval. Tesis Doctoral (Inédita). Jaén.

FATAS Y BORRAS (1993): Diccionario de términos de arte. Zaragoza, p. 17.

GARCÍA PARDO, Manuela (1998). El Cabildo de la Catedral de Jaén. Organización y vida (siglos XIII-XVI). Universidad de Almería.

LÁZARO, Ma Soledad (1988). Desarrollo histórico del casco urbano de Jaén hasta 1600. Jaén.
LÓPEZ PÉREZ, Manuel. (1996): "La Puerta Noguera de Puerta a vertedero". Senda de los Huertos $N^{\circ} 41$. EneroMarzo, pp. 45 a 47.

MADOZ, PASCUAL (1848): Diccionario geográfico estadístico histórico de España y sus posesiones de Ultramar. Madrid. (Ed. Facsimil Jaén, Jaén 1988).

MARTÍNEZ DE MAZAS, 」. (1794). Retrato al natural de la ciudad y término de Jaén. (Ed. Facsimil). Barcelona 1978.

MARÍA MOLINER (200 I): Diccionario de uso del español. segunda edición. Tomo II. Madrid.

ORTEGA SAGRISTA, Rafael (1972): "Historia de la Puerta Noguera", en Diario Jaén días 9, 10,1 1, 12 y 13 de agosto.

PARDO CRESPO, J. Ma ( 1982): "El Postigo de la Llana", en Diario Jaén de 3 de octubre.

PÉREZ MIÑANO, Carmen (2004). La ciudad de Jaén y su imagen. Jaén.

RAMÍREZ DE JUAN, Ma Eloísa (2003). Las Propiedades Urbanas de los Conventos de Jaén en el Catastro de Ensenada. Jaén.

RAMÍREZ DE JUAN, María Eloísa (2004): “La casa del presbítero Miguel López de Palma en el Catastro del Marqués de la Ensenada". Mágina, n 12. Revista Universitaria. Primavera 2004. Jaén.

RODRIGUEZ MOLINA, J (I 982): "Jaén. Organización de sus tierras y hombres (Siglos XIII-XVI)". Historia de Jaén. Jaén.

SALVATIERRA CUENCA, Vicente (1993a). El Baño del Naranjo. La formación del edificio de los Caños. Jaén.

SALVATIERRA CUENCA, Vicente (1993b): "Jaén en los siglos XIII y XIV. La formación de la ciudad cristiana". Revista del centro de Estudios Históricos de Granada y su reino. № 7, Granada, pp. 149-167

ULIERTE VÁZQUEZ, Luz. Jaén, la ciudad y su historia. Centro de Estudios Municipales y de cooperación Interprovincial. Granada, 1990. 


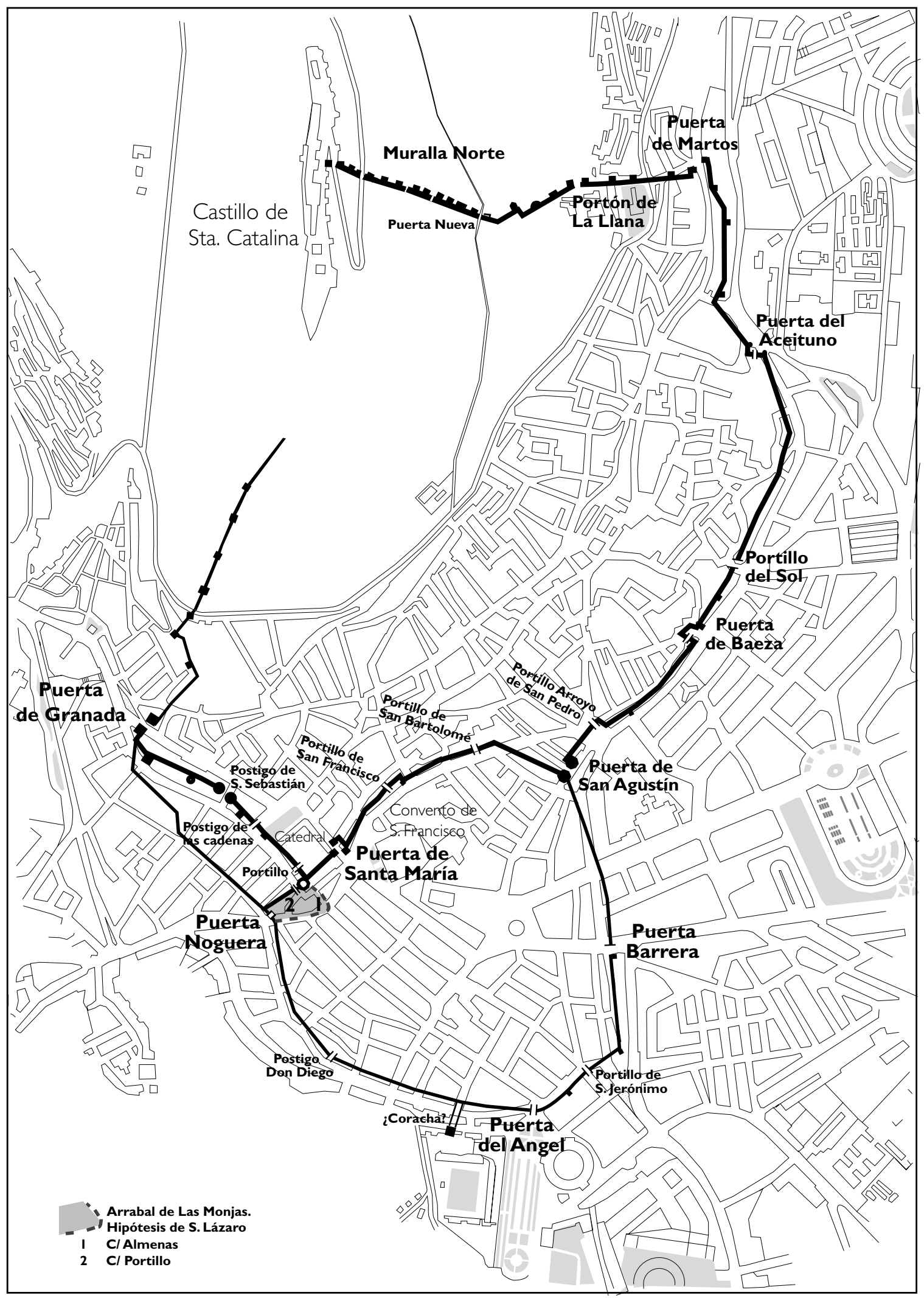

Fig. I. Plano de Jaén y trazado de la muralla medieval. 


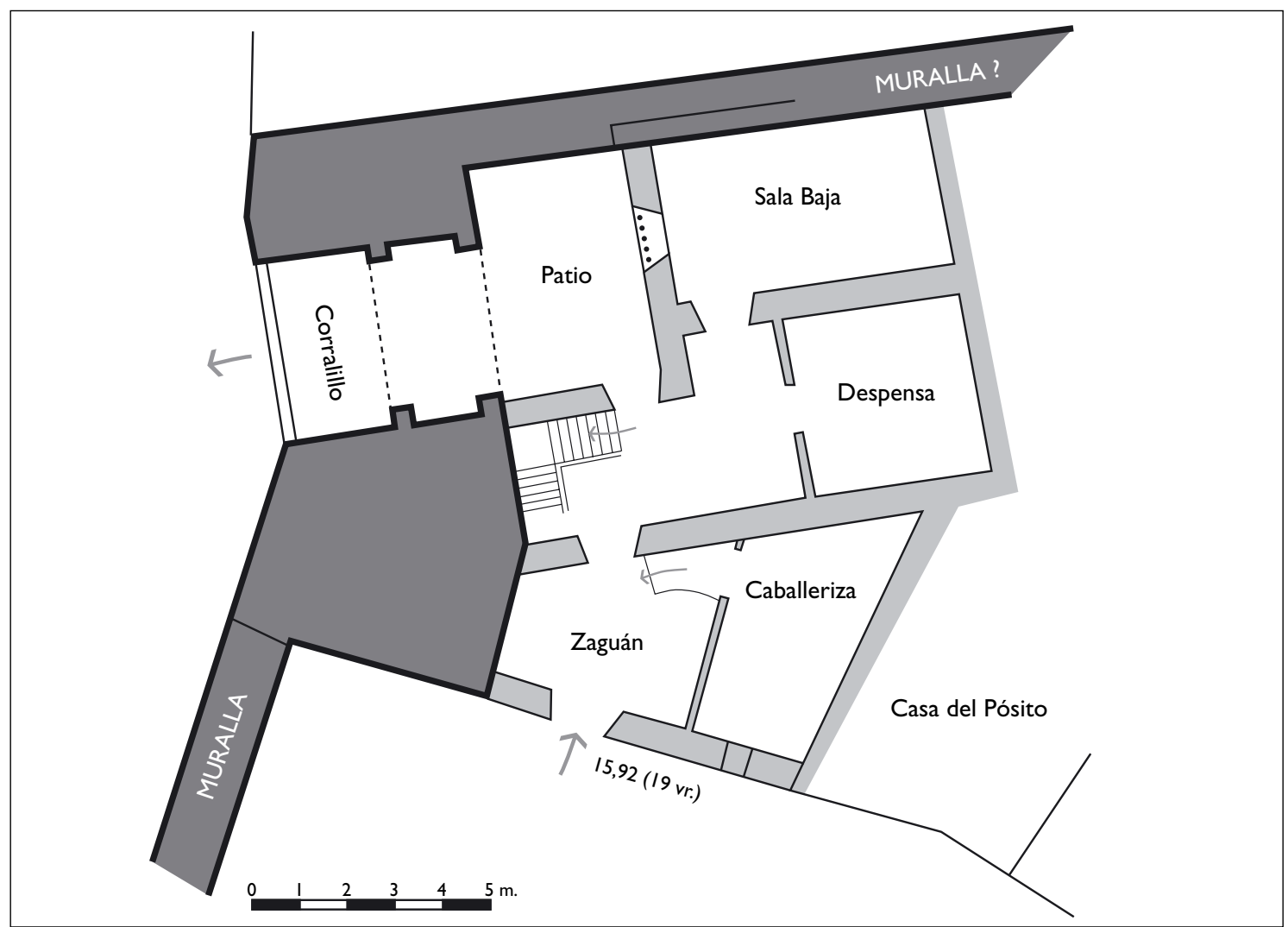

Fig. 2. Casa adosada a la muralla. Plano de la planta baja

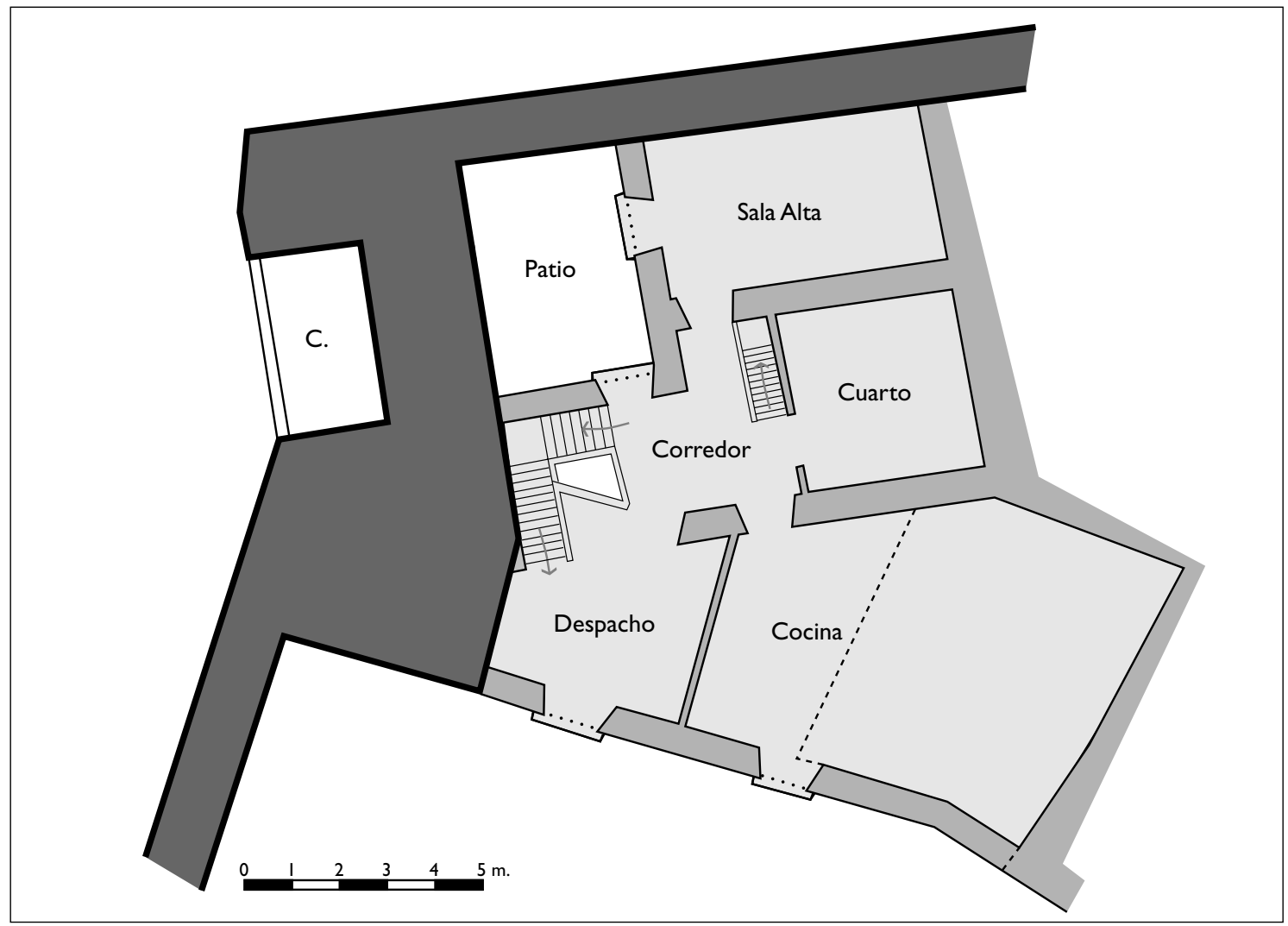

Fig. 3. Plano de la planta alta. 


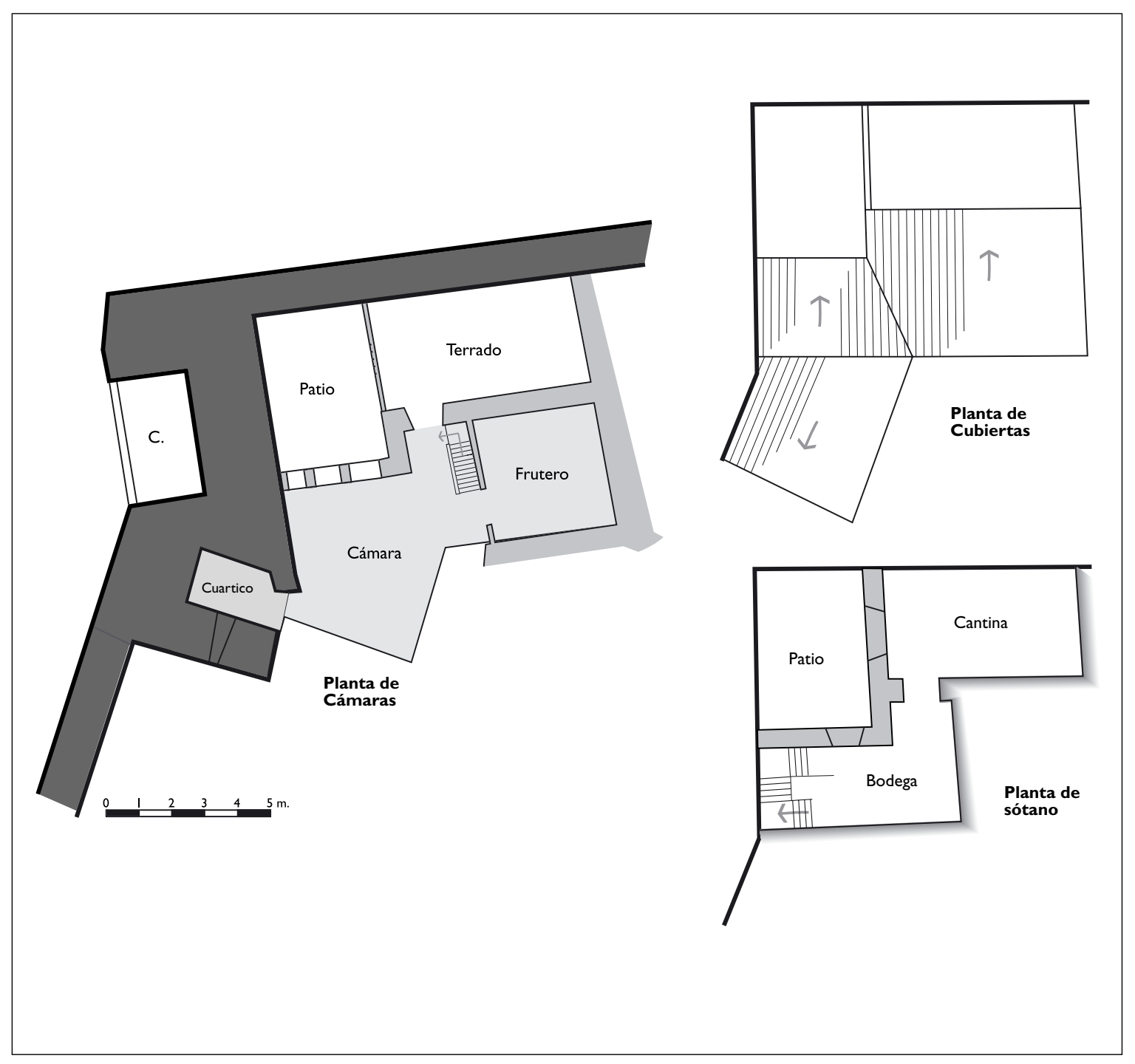

Fig. 4. Resto de plantas. 


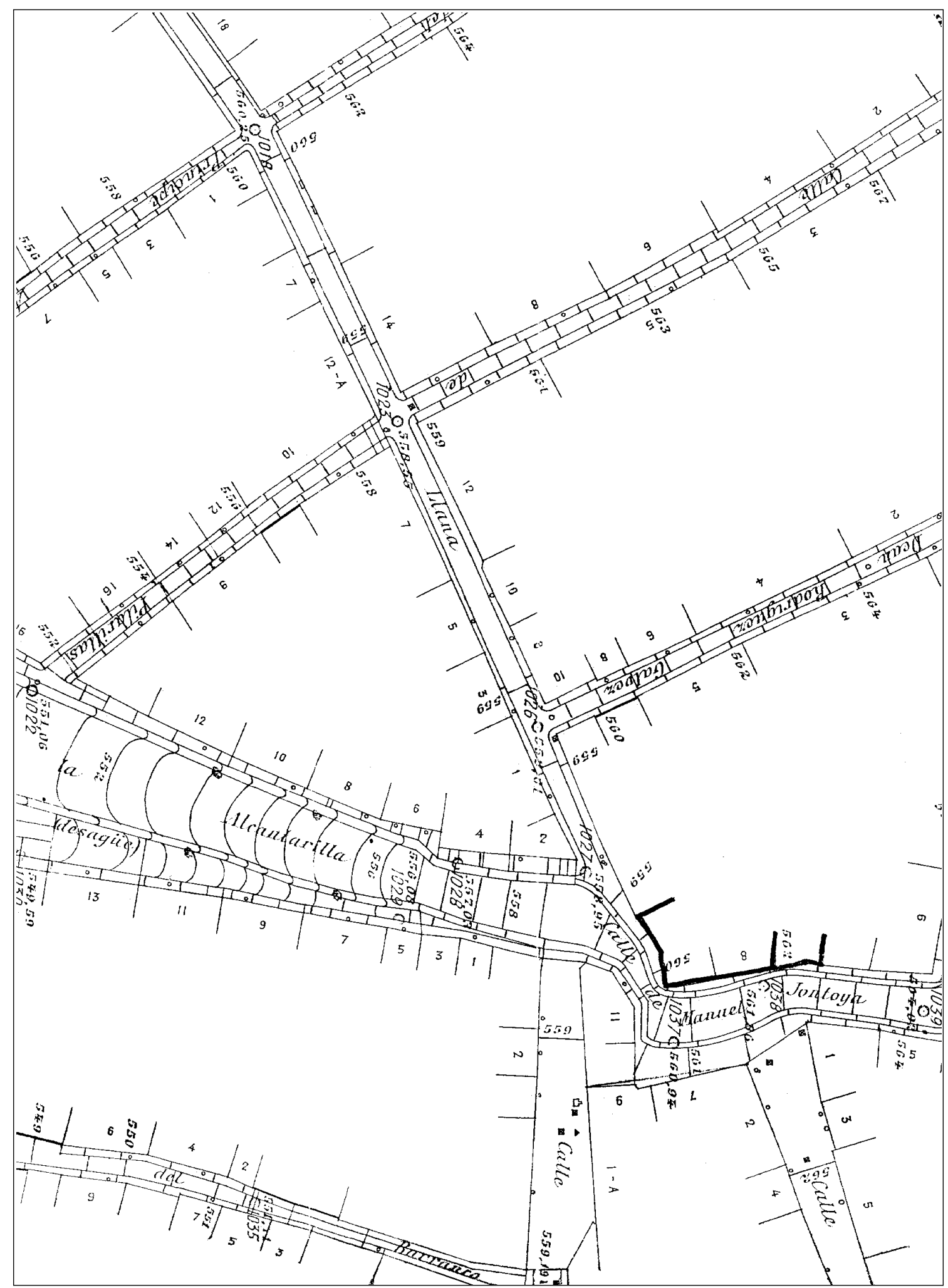

Fig. 5. Plano de Jaén de Antonio Revenga (1945). 


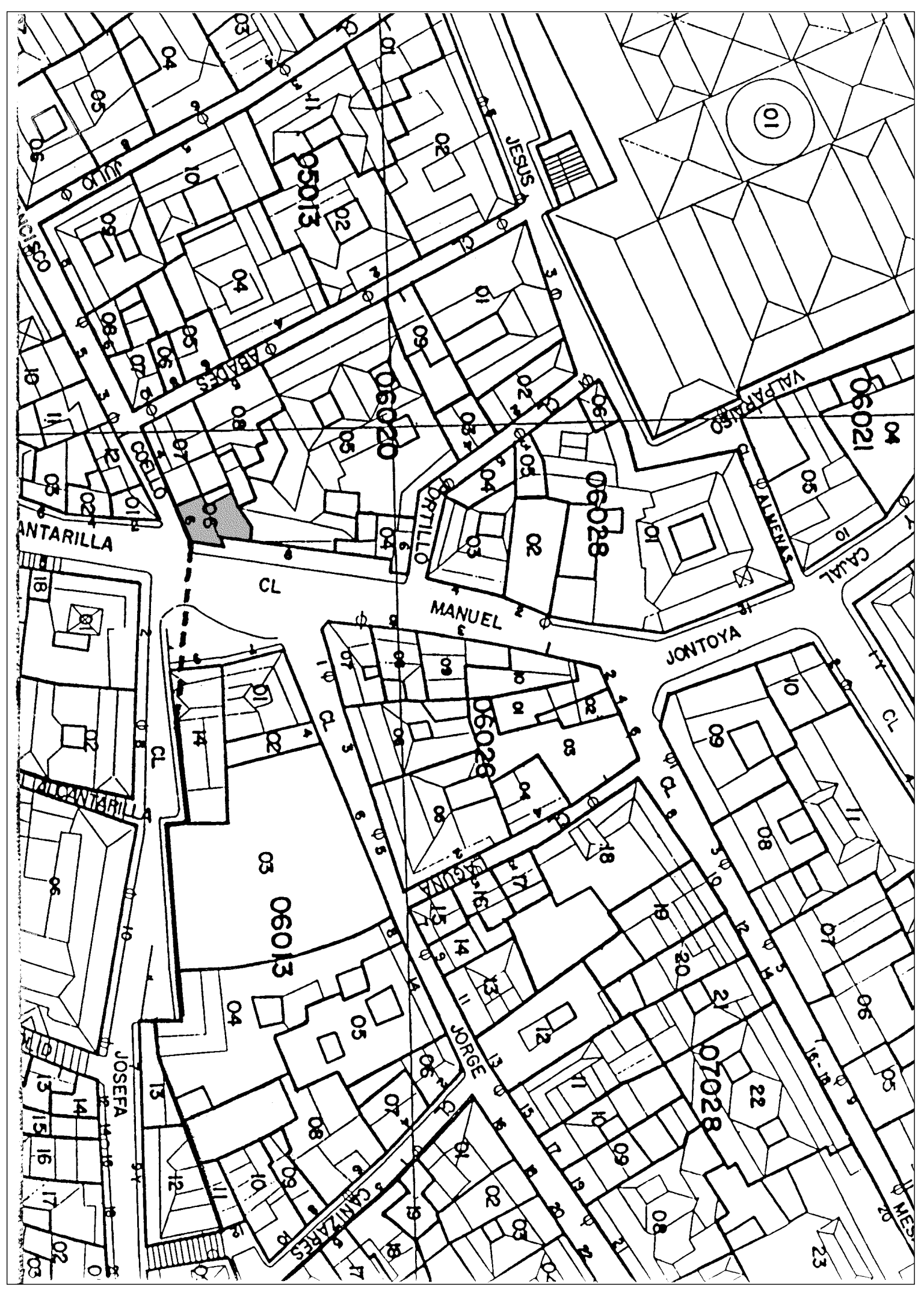

Fig. 6. 


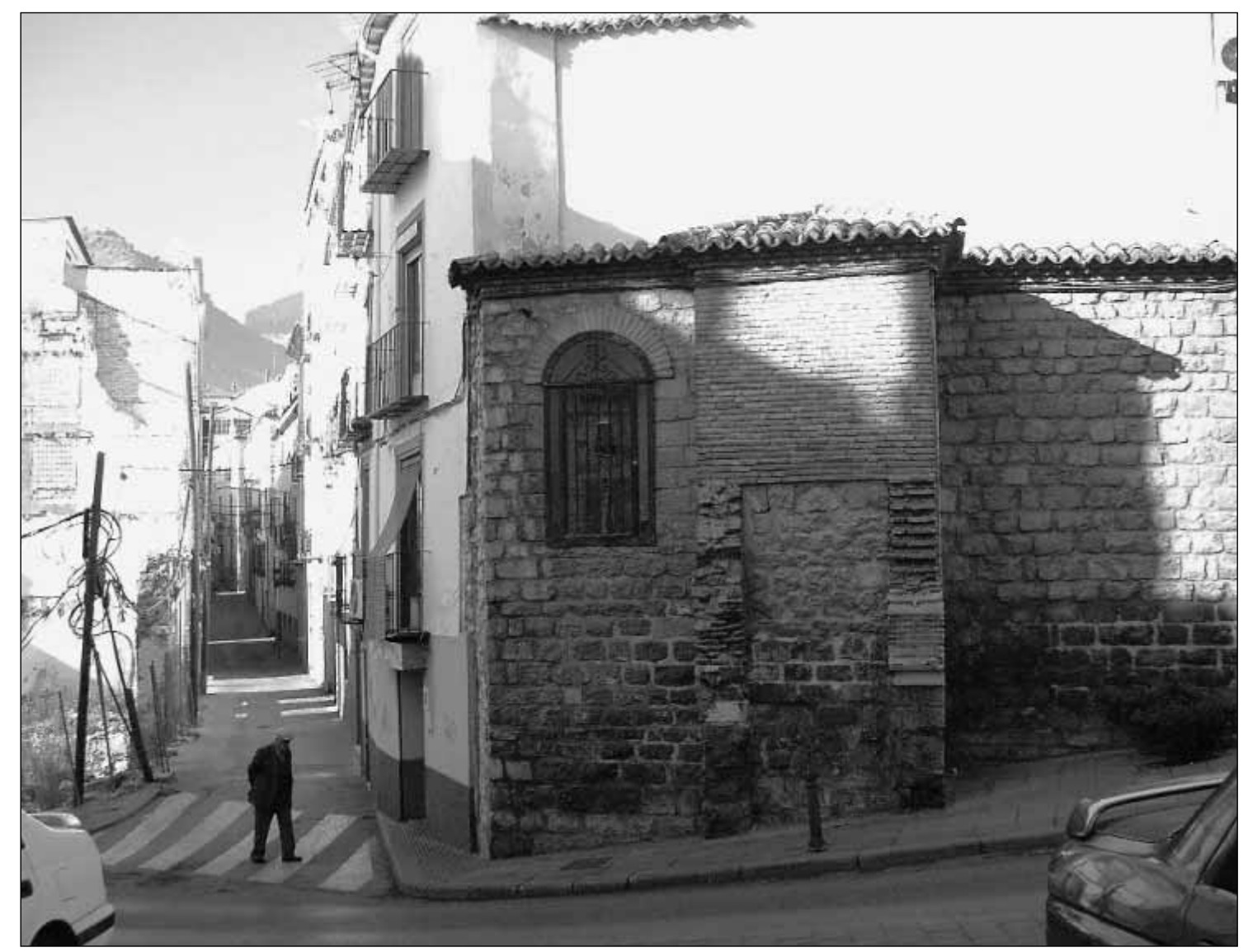

Lámina I.

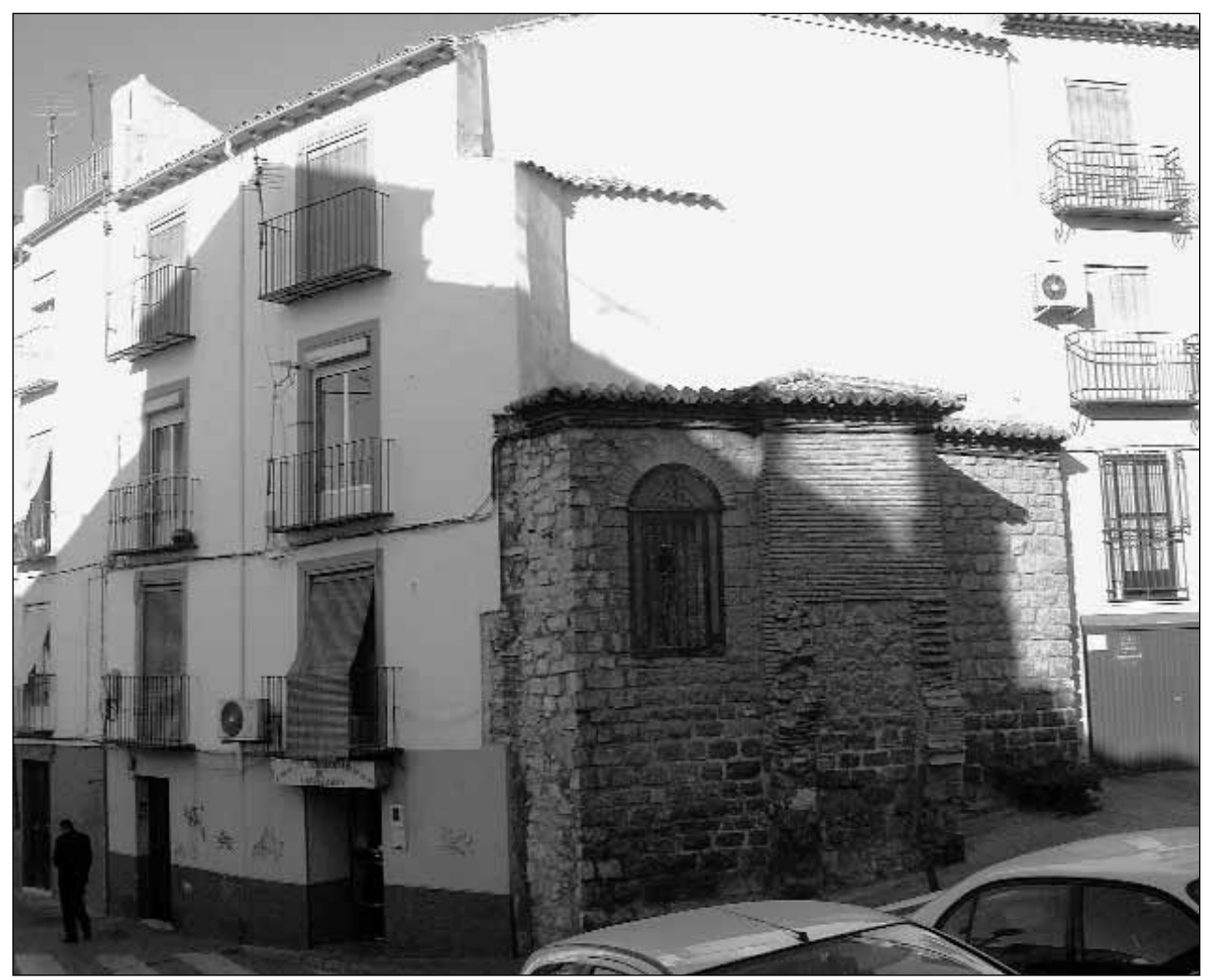

Lámina 2. 


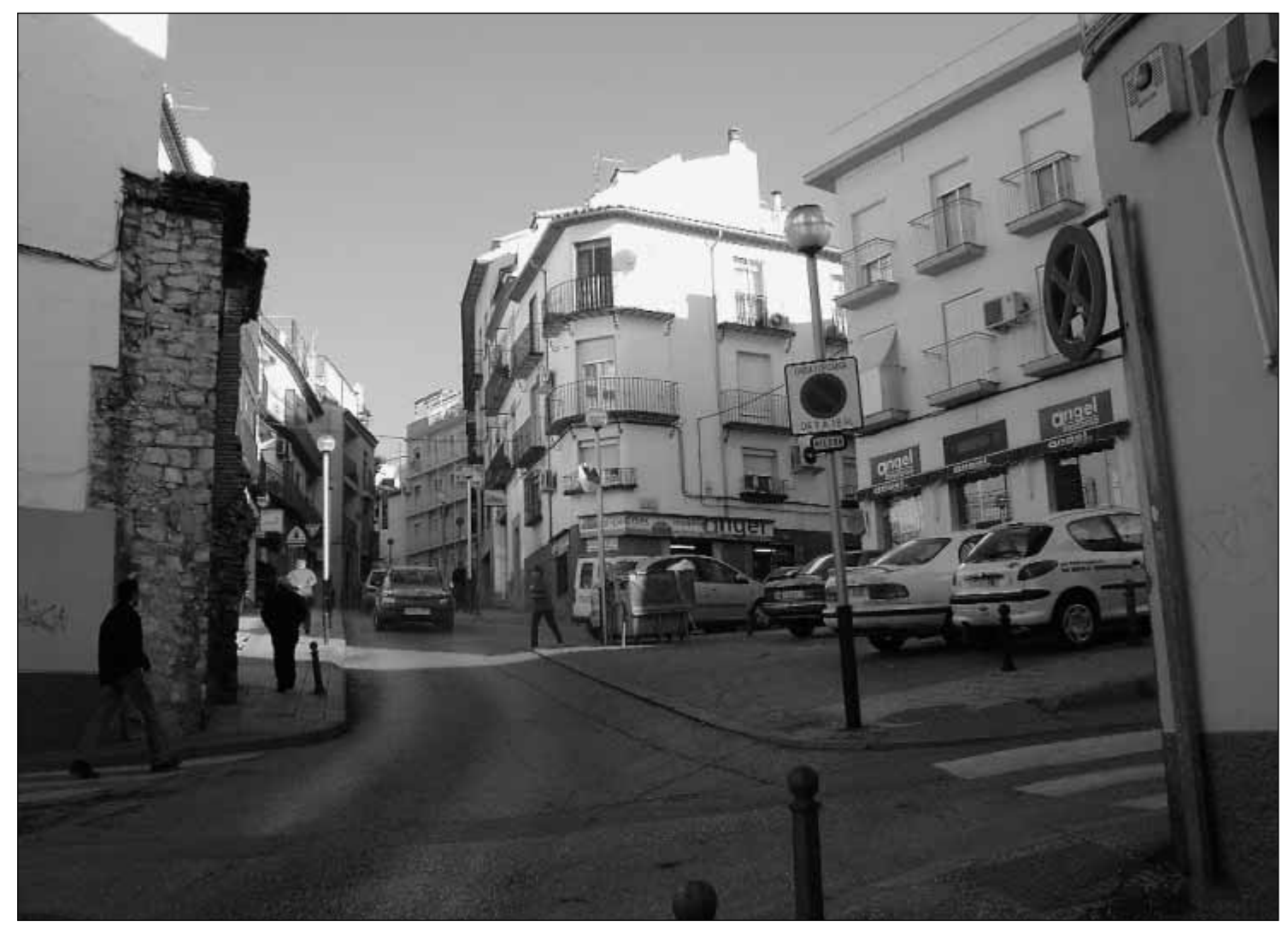

Lámina 3.

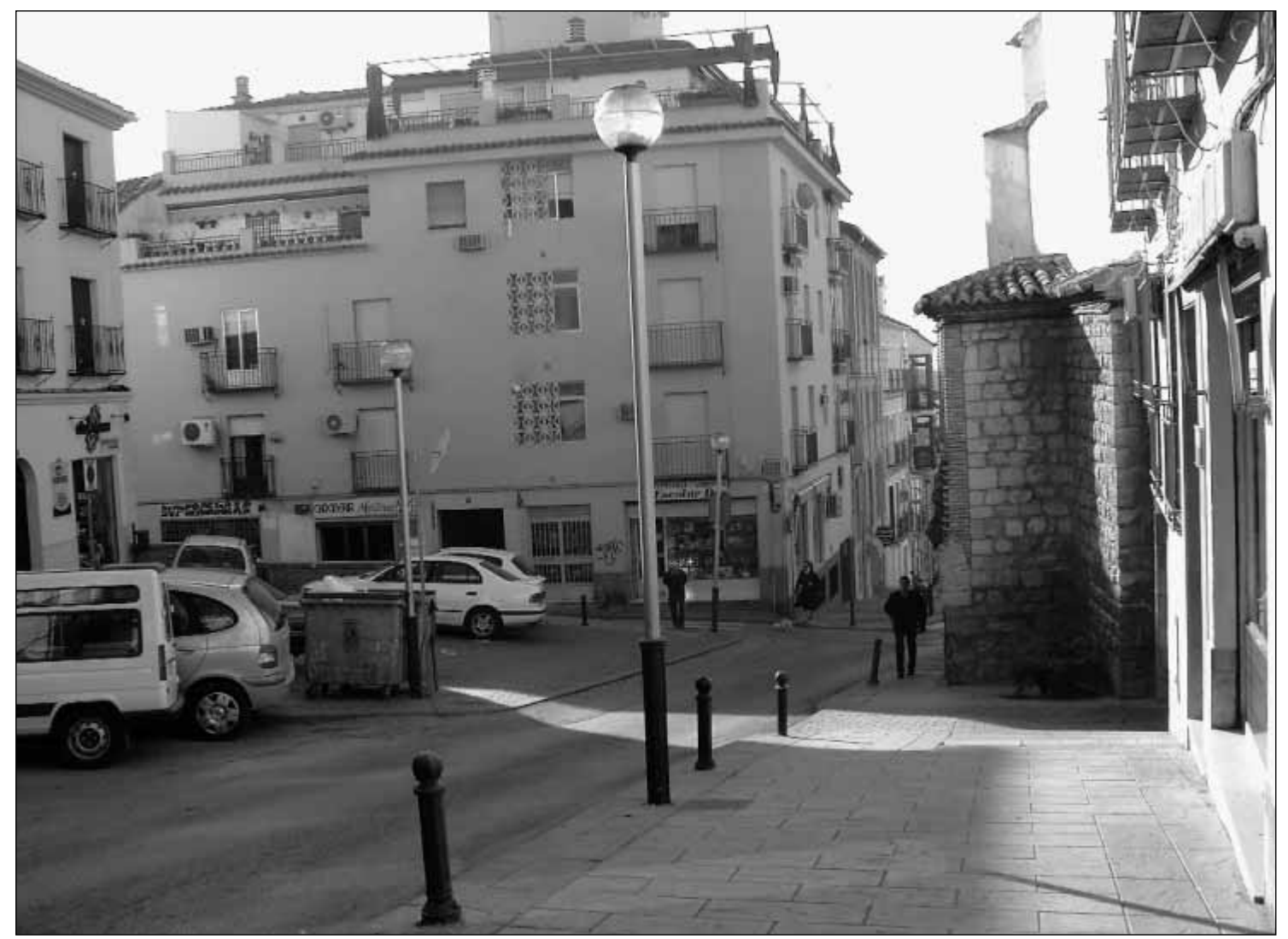

Lámina 4. 